\title{
Clinical factors influencing the resting and stimulated salivary flow
}

\author{
Shigeo Yamachika $a^{1,2}$, Ken Yamamoto ${ }^{1,3}$, Yoshiaki Nomura ${ }^{4}$, Hiroyuki Yamada $^{5}$, Ichiro Saito $^{1,6}$, \\ Yoichi Nakagawa ${ }^{1,2}$ \\ ${ }^{1}$ Department of Clinical Pathophysiology, School of Dental Medicine, Tsurumi University, Yokohama, Japan \\ ${ }^{2}$ Department of Oral Medicine and Stomatology, School of Dental Medicine, Tsurumi University, Yokohama, Japan \\ ${ }^{3}$ Department of Geriatric Dentistry, School of Dental Medicine, Tsurumi University, Yokohama, Japan \\ ${ }^{4}$ Department of Translational Research, School of Dental Medicine, Tsurumi University, Yokohama, Japan \\ ${ }^{5}$ Department of Oral and Maxillofacial Surgery, School of Dental Medicine, Tsurumi University, Yokohama, Japan \\ ${ }^{6}$ Department of Pathology, School of Dental Medicine, Tsurumi University, Yokohama, Japan \\ Email: nakagawa-y@tsurumi-u.ac.jp
}

Received 22 March 2012; revised 13 April 2012; accepted 24 April 2012

\begin{abstract}
Objective: The objective of this study was to examine the clinical and immunological factors influencing sialometry in xerostomia patients. Method: The association between sialometry and other clinical examinations were investigated in a cross-sectional study. A total of 179 dry mouth patients showing hyposalivation who underwent a clinical examination were enrolled in this study. Multiple regression analyses were employed to examine the relative contributions of clinical and immunological factors including age, gender, parotid sialography, labial Salivary gland biopsy, anti-Ro/SS-A antibodies, and antiLa/SS-B antibodies to the resting (RSF) or stimulated saliva flow rate (SSF). Results: An increase of the stage of sialography, the grade of a labial biopsy, and the presence of anti-La/SS-B antibody had a significant correlation with a decrease of sialometry. Results of the multiple regression analysis showed that age (standardized coefficient $=\mathbf{- 0 . 2 4 4}$ ), grade of lip biopsy $(-0.189)$, and anti-SS-B antibody $(-0.171)$, were significantly associated with the RSF. The stage of sialography $(-0.423)$ and age $(-0.169)$ were significantly related to the sialometry in the SSF according to a multiple regression analysis. Conclusion: The results of this study suggest that the measurement of RSF reflects the immunological factors and SSF reflects the damage to the parotid gland.
\end{abstract}

Keywords: Xerostomia; Sialometry; Sialography; Labial Minor Salivary Gland Biopsy; Sjögren's Syndrome

\section{INTRODUCTION}

Sjögren's syndrome is an autoimmune exocrinopathy characterized by lymphocytic infiltration in the salivary and lacrimal glands resulting in dry mouth and dry eyes [1]. The changes in salivary glands in the Sjögren's syndrome are usually evaluated in two different ways, by a functional and morphologic assessment of the salivary gland. Salivary gland function is assessed through measurement of the salivary secretion rate (sialometry) and analysis of salivary composition (sialochemistry). Morphologic assessment includes biopsy of the labial gland, and salivary gland imaging. Several procedures are performed for gland imaging, magnetic resonance imaging (MRI), computed tomography (CT) scanning, ultrasonography, scintigraphy, and sialography $[1,2]$.

Since the etiology of Sjögren's syndrome remains unclear, the diagnosis is based on the presence of characteristic signs and symptoms. A variety of diagnostic criteria requiring different combinations of examination have been proposed to diagnose Sjögren's syndrome [3]. Recently, the American-European consensus group proposed a revised version of the European criteria [4]. A similar original criterion suggested by the Japanese Ministry of Health and Welfare has been widely used in Japan [5]. Both criteria employ sialometry, sialography, minor salivary gland biopsy and detection of serum autoantibody to SS-A and/or SS-B as clinical examinations.

Sialometry is simple and fundamental examination procedure for evaluating salivary function, and there are two different measurements methods, resting (unstimulated) saliva flow rate (RSF) and whole stimulated saliva flow rate (SSF). The criterion proposed by the AmericanEuropean consensus group employs RSF, while the Japanese criterion employs SSF. The patients show whole resting salivary flow rates less than $1.5 \mathrm{~mL} / 15 \mathrm{~min}$, or whole stimulated salivary flow rates less than 10 
$\mathrm{mL} / 10 \mathrm{~min}$ were classified as hyposalivation according to the previously determined criteria [3-5].

Hyposalivation is attributed not only to the destruction of the gland, but also to the dysfunction of residual glandular element in the salivary glands $[1,6,7]$. The local environment of an inflamed gland leads to dysfunction on the residual glandular tissue, in which cytokines and autoantibodies play an important role for salivary function [8]. However, which clinical parameters contribute the hyposalivation is unclear. Clarification of the clinical factors is essential to elucidate the pathophysiology in Sjögren's syndrome.

The purpose of the study was to clarify the clinical and immunological factors influencing on hyposalivation. The correlation between hyposalivation and clinical and immunological data such as gender, age, sialography, lip biopsy and antibodies to SS-A/SS-B were examined using a multiple logistic regression analysis.

\section{PATIENTS AND METHODS}

\subsection{Study Design}

The association between the results of sialometry and other clinical parameters were investigated in a crosssectional study.

\subsection{Patients}

This study analyzed data from 179 Japanese patients who visited the Dry Mouth Clinic of Tsurumi University Dental Hospital with complaints of xerostomia between November 2002 and October 2006. The patients who showed hyposalivation and underwent clinical examinations such as sialometry and sialography, lip biopsy, or serological examinations were included in the study. Patients who did not agree to undergo examinations were excluded from the study. Patients who had a medical history of significant cardiovascular disease, significant pulmonary obstructive disease, gastrointestinal obstructive disease, epilepsy, Parkinson's disease, or radiation therapy for head and neck region were also excluded.

The diagnosis of Sjögren's syndrome was based on the revised diagnostic criteria for Sjögren's syndrome by the Committee on Sjögren's syndrome of the Ministry of Health and Welfare of Japan [5] and the Sjögren's syndrome criteria proposed by the American-European consensus group [4].

\subsection{Sialometry}

Both resting (unstimulated) and stimulated whole saliva samples were collected using the "spit" method [9]. Patients were instructed not to eat, drink, smoke, chew, or perform oral hygiene for 60 minutes prior to saliva collection. For RSF, saliva was collected in a tube for 15 minutes.

SSF (gum test) was determined by measuring a volume of stimulated whole saliva, which was stimulated by chewing a piece of gum (Free zone gum, Lotte Co., Ltd., Tokyo, Japan). Stimulated saliva from the oral cavity was collected in a tube for 10 minutes. Saliva volumes were measured by aspirating saliva with a disposable syringe.

RSF less than $1.5 \mathrm{~mL} / 15 \mathrm{~min}$ and SSF less than 10 $\mathrm{mL} / 10 \mathrm{~min}$ were classified as hyposalivation according to previously determined criteria $[4,5]$.

\subsection{Sialography}

Sialography of the unilateral parotid gland was performed using the conventional hand-injection method. A lateral projection was taken immediately after the injection of $1 \mathrm{ml}$ of contrast medium $76 \%$ diatrizoate sodium (Urografin: Nihon Schering Co., Ltd., Osaka, Japan) into the Stensen's duct. After the addition of $0.5 \mathrm{ml}$ of contrast medium, a posterior-anterior radiograph was taken. Two trained examiners evaluated the sialography findings in all cases according to the classification of Rubin and Holt [10]; Stage 0, normal; Stage I, punctate; Stage II, globular; Stage III, cavitary; and Stage IV, destructive. Stages I-IV was considered to be positive according to the Sjögren's syndrome criteria [4,5].

\subsection{Labial Minor Salivary Gland Biopsy}

Biopsy specimens were obtained through normal appearing lower labial mucosae. Three trained pathologists evaluated the focal lymphocytic sialoadenitis in the minor salivary glands by hematoxylin and eosin (HE) stained sections according to Greenspan's criteria [11]; Grade 0, absent; Grade 1, slight infiltrate; Grade 2, moderate infiltrate or less than one focus per $4 \mathrm{~mm}^{2}$; Grade 3, one focus per $4 \mathrm{~mm}^{2}$; and Grade 4, more than one focus per $4 \mathrm{~mm}^{2}$. Grades 3 and 4 were considered to be positive according to the Sjögren's syndrome criteria $[4,5]$.

\subsection{Antibody Determination}

Serum antibodies to Ro/SS-A and La/SS-B were measured using an enzyme-linked immunosorbent assay (ELISA) which was performed at BRL laboratories (Tokyo, Japan).

\subsection{Data Analysis}

A one-way analysis of variance was used to check the effects of the clinical factors for the sialometry. Regression analyses were used to examine and calculate the weight of the factors influencing the sialometry. A multiple regression analysis was used to obviate the problems of confounding factors. The objective variable was 
the RSF or SSF. Age, gender, sialography, minor salivary gland biopsy, anti-Ro/SS-A antibodies and anti-La/SS-B antibodies were regarded as predictors. In addition, a stepwise multivariate regression analysis was used to construct the formula for the statistically prediction of the saliva volume by clinical factors. A p-value less than 0.05 was considered to be statistically significant. These analyses were carried out using the SPSS ver. 17.0 software package (SPSS Co., Ltd., Tokyo, Japan).

\subsection{Ethics}

The study involved patients who understood the purpose of the examination and gave investigators permission to use the data obtained. Finally, the Ethical Committee of Tsurumi University approved this study.

\section{RESULTS}

\subsection{Summary Statistics}

A total of 179 patients (16 male and 163 female; mean age of $61.7 \pm 12.0$, range $21-83$ years) were examined. The subjects included $85(44.7 \%)$ patients with Sjögren's syndrome who satisfied the Sjögren's syndrome criteria proposed by Japanese Ministry of Health and Welfare [5], and/or American-European consensus group [4].

Tables 1 and $\mathbf{2}$ show the descriptive statistics in the RSF and in the SSF data, respectively. The one-way analysis of variance showed no significant difference between male and female in the RSF $(0.531 \pm 0.528$ and $0.513 \pm 0.688$, respectively; Table 1), and that in the SSF $(4.853 \pm 2.102$ and $5.378 \pm 3.082$, respectively; Table 2$)$. There was no significant difference among the age groups. In the serological examinations, significant difference between positive and negative groups was observed both in the RSF (Table 1) and SSF (Table 2). Similarly, sialography showed significant differences among 5 groups in both in the RSF and SSF. The labial biopsy examination identified a significant difference among 5 groups in the SSF.

\subsection{Factors Influencing the RSF}

A simple regression analysis showed that age, SS-A, SS-B, sialography, and labial biopsy was significantly related to the sialometry (left side column in the Table 3). A multiple regression model showed a significant correlation between RSF and age (coefficient $=-0.165, p=$ 0.001 ; right side column in Table 3). Although the sialogram and labial biopsy may strongly influence the sialometry findings (coefficient $=-0.311$ in sialogram and coefficient $=-0.141$ in labial biopsy), no significant correlation was observed between them $(p=0.264$ and $p=$ 0.092, respectively).

A stepwise multivariate regression analysis was used
Table 1. Clinical factors influencing the resting saliva flow rate.

\begin{tabular}{|c|c|c|c|c|}
\hline \multirow{2}{*}{\multicolumn{2}{|c|}{ Clinical factors }} & \multirow{2}{*}{$\mathrm{n}$} & Saliva flow & \multirow{2}{*}{$p$ Value ${ }^{*}$} \\
\hline & & & Mean \pm SD & \\
\hline \multirow{2}{*}{ Sex } & Male & 16 & $0.531 \pm 0.528$ & \multirow{2}{*}{0.611} \\
\hline & Female & 163 & $0.513 \pm 0.688$ & \\
\hline \multirow{7}{*}{ Age } & $21-30$ & 4 & $1.750 \pm 2.062$ & \multirow{7}{*}{0.269} \\
\hline & $31-40$ & 9 & $0.567 \pm 0.594$ & \\
\hline & $41-50$ & 13 & $0.692 \pm 0.520$ & \\
\hline & $51-60$ & 41 & $0.470 \pm 0.655$ & \\
\hline & $61-70$ & 72 & $0.496 \pm 0.663$ & \\
\hline & $71-80$ & 35 & $0.446 \pm 0.415$ & \\
\hline & $81-$ & 5 & $0.100 \pm 0.173$ & \\
\hline \multirow{2}{*}{ SS-A } & Negative & 112 & $0.612 \pm 0.737$ & \multirow{2}{*}{0.007} \\
\hline & Positive & 61 & $0.352 \pm 0.520$ & \\
\hline \multirow{2}{*}{ SS-B } & Negative & 145 & $0.580 \pm 0.718$ & \multirow{2}{*}{0.002} \\
\hline & Positive & 27 & $0.193 \pm 0.243$ & \\
\hline \multirow{5}{*}{ Sialography } & Stage 0 & 115 & $0.633 \pm 0.736$ & \multirow{5}{*}{0.003} \\
\hline & Stage 1 & 31 & $0.406 \pm 0.593$ & \\
\hline & Stage 2 & 23 & $0.209 \pm 0.287$ & \\
\hline & Stage 3 & 9 & $0.211 \pm 0.457$ & \\
\hline & Stage 4 & 1 & 0.100 & \\
\hline \multirow{5}{*}{ Lip biopsy } & Grade 0 & 60 & $0.675 \pm 0.856$ & \multirow{5}{*}{0.064} \\
\hline & Grade 1 & 30 & $0.445 \pm 0.522$ & \\
\hline & Grade 2 & 24 & $0.617 \pm 0.574$ & \\
\hline & Grade 3 & 17 & $0.253 \pm 0.287$ & \\
\hline & Grade 4 & 32 & $0.291 \pm 0.343$ & \\
\hline
\end{tabular}

*The $t$-test was used for comparison between two groups, and a one way analysis of variance (ANOVA) was used for more than three groups.

to determine the variables that influence hyposalivation (Table 4) with age, grade of labial biopsy, and positive/ negative anti SS-B as the possible predictive factors for the resting salivary volume because the $p$ values were relatively small $(p=0.001, p=0.018$ and $p=0.033$, respectively). RSF was predicted by the model; predicted $\operatorname{RSF}(\mathrm{mL} / 15 \mathrm{~min})=1.503-(0.013 \times$ age $*)-(0.310 \times$ anti-La/SS-B antibody** $)-(0.080 \times$ grade of labial biopsy***).

*Age: 21 - 30, 0; 31 - 40, 1; 41 - 50, 2; 51 - 60, 3; 61 70, 4; 71 - 80, 5; 81 - 90, 6;

**Anti-La/SS-B antibodies: Negative, 0; Positive, 1;

***Minor salivary gland biopsy: Grade 0,0 ; 
Table 2. Clinical factors influencing the stimulated saliva flow rate.

\begin{tabular}{|c|c|c|c|c|}
\hline \multirow{2}{*}{\multicolumn{2}{|c|}{ Clinical factors }} & \multirow{2}{*}{$\mathrm{n}$} & Saliva flow & \multirow{2}{*}{$p$ Value ${ }^{*}$} \\
\hline & & & Mean \pm SD & \\
\hline \multirow{2}{*}{ Sex } & Male & 16 & $4.853 \pm 2.102$ & \multirow{2}{*}{0.611} \\
\hline & Female & 163 & $5.378 \pm 3.082$ & \\
\hline \multirow{7}{*}{ Age } & $21-30$ & 4 & $5.325 \pm 3.754$ & \multirow{7}{*}{0.593} \\
\hline & $31-40$ & 9 & $6.511 \pm 4.047$ & \\
\hline & $41-50$ & 13 & $6.585 \pm 2.663$ & \\
\hline & $51-60$ & 41 & $4.871 \pm 2.820$ & \\
\hline & $61-70$ & 72 & $5.320 \pm 3.016$ & \\
\hline & $71-80$ & 35 & $5.214 \pm 2.896$ & \\
\hline & 81- & 5 & $4.800 \pm 3.938$ & \\
\hline \multirow{2}{*}{ SS-A } & Negative & 112 & $6.020 \pm 2.922$ & \multirow{2}{*}{$<0.001$} \\
\hline & Positive & 61 & $4.252 \pm 2.889$ & \\
\hline \multirow{2}{*}{ SS-B } & Negative & 145 & $5.747 \pm 3.079$ & \multirow{2}{*}{$<0.001$} \\
\hline & Positive & 27 & $3.589 \pm 1.931$ & \\
\hline \multirow{5}{*}{ Sialography } & Stage 0 & 115 & $6.283 \pm 3.007$ & \multirow{5}{*}{$<0.001$} \\
\hline & Stage 1 & 31 & $4.361 \pm 2.218$ & \\
\hline & Stage 2 & 23 & $2.991 \pm 2.141$ & \\
\hline & Stage 3 & 9 & $2.789 \pm 1.381$ & \\
\hline & Stage 4 & 1 & 4.000 & \\
\hline \multirow{5}{*}{ Lip biopsy } & Grade 0 & 60 & $6.103 \pm 2.889$ & \multirow{5}{*}{0.003} \\
\hline & Grade 1 & 30 & $6.053 \pm 3.144$ & \\
\hline & Grade 2 & 24 & $4.752 \pm 2.573$ & \\
\hline & Grade 3 & 17 & $4.724 \pm 2.761$ & \\
\hline & Grade 4 & 32 & $3.931 \pm 2.471$ & \\
\hline
\end{tabular}

*The $t$-test was used for comparison between two groups, and a one way analysis of variance (ANOVA) was used for more than three groups.

Grade 1, 1; Grade 2, 2; Grade 3, 3; Grade 4, 4.

\subsection{Factors Influencing the SSF}

A simple regression analysis showed that anti SS-A and SS-B, sialogram, and labial biopsy were significantly related to the sialometry (Table 5). The multiple regression analysis showed age and the sialogram stages were significantly related to the sialometry $(p=0.024, p=$ 0.001 , respectively).

A stepwise multivariate regression analysis evaluated age and stage of sialography as predictive factors $(p<$ 0.001 and $p=0.020$ ) for stimulating salivary volume (Table 6). These variables of salivary volume calculated the SSF by the model $\left(\mathrm{R}^{2}=0.146\right)$; predicted SSF $(\mathrm{mL} / 15 \mathrm{~min})=8.733-\left(0.041 \times\right.$ age $\left.^{*}\right)-(1.339 \times$ stage of sialogram**).

*Age: 21 - 30, 0; 31 - 40, 1; 41 - 50, 2; 51 - 60, 3; 61 70,$4 ; 71-80,5 ; 81-90,6$;

**Parotid sialography: Stage 0, 0; Stage 1, 1;

Stage 2, 2; Stage 3, 3; Stage 4, 4.

\section{DISCUSSION}

The present results suggested that the age, grade of labial biopsy, and positive/negative of anti-La/SS-B were predictive factors for resting salivary volume, and the age and stage of sialography were predictive factors for stimulated salivary volume.

The relationship between salivary flow rate and aging is controversial. Several studies suggest that aging does not necessarily result in degeneration of salivary gland function, and it is considered to be a disease- and/or medication-related condition $[12,13]$. Longitudinal studies also demonstrate that there is no decline with increasing age [14-16]. In contrast, morphological studies show that there is substantial age-related replacement of the functional parenchymal tissue by non-functioning adipose and fibrous tissue in the salivary glands of elderly people, regardless of whether or not drugs are taken $[17,18]$. This replacement is accompanied not only by a reduction of the salivary flow rate, but also by a reduction in salivary protein production and other induced alterations in composition [19,20]. In addition to the morphological changes with aging $[21,22]$, an impairment of the signal transduction in the salivary gland cell has previously been recognized in animal studies $[23,24]$. The present results demonstrated that age was significantly related to the decrease both of resting and stimulated salivary flow when examined by a stepwise multivariate regression analysis. The disease course in pediatric Sjögren's syndrome cases is insidious, showing a lower incidence of dry mouth symptoms, although the pathological and laboratory findings in children with Sjögren's syndrome are similar to those in adults [25]. The disease may progress gradually with aging, and it may be many years before such patients develop endstage characteristics.

The resting salivary volume in the present study was significantly related to the grades of the labial biopsy and the detection of the serum autoantibody, anti-La/SS-B. The submandibular glands normally contribute about $65 \%$ of the total volume of unstimulated saliva, while the parotid glands contribute $20 \%$ [26]. Therefore, the results of RSF are possibly depended on the submandibular gland function. The changes in the submandibular glands might be similar to that in the other salivary glands, although they were not directly examined in the present study. 
Table 3. Simple and multiple regression of the resting saliva flow rate.

\begin{tabular}{cccccccccc}
\hline & \multicolumn{3}{c}{ Simple regression analysis } & \multicolumn{3}{c}{ Multiple regression analysis } \\
\hline Clinical factors & Coeffcient $(\beta)$ & SE & $\begin{array}{c}\text { Standardized } \\
\text { coefficient }(\beta)\end{array}$ & $p$ Value & Coeffcient $(\beta)$ & SE & $\begin{array}{c}\text { Standardized } \\
\text { coefficient }(\beta)\end{array}$ & $p$ Value \\
\hline Sex & -0.018 & 0.177 & -0.008 & 0.919 & 0.829 & 0.802 & 0.075 & 0.572 \\
Age & -0.011 & 0.004 & -0.192 & 0.010 & -0.040 & 0.018 & -0.165 & 0.001 \\
SS-A & -0.260 & 0.106 & -0.183 & 0.016 & -0.392 & 0.591 & -0.064 & 0.897 \\
SS-B & -0.388 & 0.140 & -0.208 & 0.006 & -0.451 & 0.723 & -0.056 & 0.165 \\
Sialography & -0.176 & 0.053 & -0.244 & 0.001 & -0.985 & 0.288 & -0.311 & 0.264 \\
Lip biopsy & -0.095 & 0.032 & -0.226 & 0.004 & -0.267 & 0.155 & -0.141 & 0.092 \\
\hline
\end{tabular}

Table 4. Stepwise multivariate regression analysis for the resting saliva flow rate.

\begin{tabular}{ccccc}
\hline Clinical factors & Coeffcient $(\beta)$ & SE & Standardized coefficient $(\beta)$ & $p$ Value \\
\hline Intercept & 1.503 & 0.266 & & \\
Age & -0.013 & 0.004 & -0.244 & 0.001 \\
SS-B & -0.310 & 0.144 & -0.171 & 0.033 \\
Lip biopsy & -0.080 & 0.033 & -0.189 & 0.018 \\
\hline
\end{tabular}

Table 5. Simple and multiple regression of the stimulated saliva flow rate.

\begin{tabular}{cccccccccc}
\hline & \multicolumn{3}{c}{ Simple regression analysis } & \multicolumn{3}{c}{ Multiple regression analysis } \\
\hline Clinical factors & Coeffcient $(\beta)$ & SE & $\begin{array}{c}\text { Standardized } \\
\text { coefficient }(\beta)\end{array}$ & $p$ Value & Coeffcient $(\beta)$ & SE & $\begin{array}{c}\text { Standardized } \\
\text { coefficient }(\beta)\end{array}$ & $p$ Value \\
\hline Sex & 0.525 & 0.814 & 0.049 & 0.520 & -0.103 & 0.181 & -0.043 & 0.303 \\
Age & -0.023 & 0.019 & -0.091 & 0.227 & -0.014 & 0.004 & -0.252 & 0.024 \\
SS-A & -1.767 & 0.464 & -0.280 & $<0.001$ & -0.018 & 0.139 & -0.013 & 0.508 \\
SS-B & -2.158 & 0.615 & -0.261 & 0.001 & -0.237 & 0.170 & -0.131 & 0.534 \\
Sialography & -1.372 & 0.220 & -0.426 & $<0.001$ & -0.076 & 0.068 & -0.107 & 0.001 \\
Lip biopsy & -0.556 & 0.142 & -0.296 & $<0.001$ & -0.061 & 0.036 & -0.145 & 0.087 \\
\hline
\end{tabular}

Table 6. Stepwise multivariate regression analysis for the stimulated saliva flow rate.

\begin{tabular}{ccccc}
\hline Clinical factors & Coeffcient $(\beta)$ & SE & Standardized coefficient $(\beta)$ & $p$ Value \\
\hline Intercept & 8.733 & 1.132 & & \\
Age & -0.041 & 0.018 & -0.169 & 0.020 \\
Sialography & -1.339 & 0.229 & -0.423 & $<0.001$ \\
\hline
\end{tabular}

The pathogenesis of Sjögren's syndrome includes several different steps. The initial steps are disruption of the homeostasis in the epithelial cells and the local endothelial venules of the salivary gland, thus resulting in increased apoptosis, aberrant protein expression, and cleavage of certain protein [1,27-30]. The later steps are characterized by the involvement of immune components
(T- and B-cells) and the generation of autoantibodies to yield the clinical symptoms of dry mouth [1,27]. The histopathological changes in the labial salivary gland biopsy characterized by focal and/or diffuse lymphoid cell infiltrates and parenchymal destruction can be detected in the latter steps. Similarly, the detection of serum autoantibodies can be recognized at this stage. Since 
autoantibodies are thought to cause a dysfunction in the saliva flow, regardless of the apparent parenchymal destruction, immunological factors are important for Salivary function $[8,31]$. Such immunological changes in the glands may possibly contribute to a decrease in the resting salivary flow rate in Sjögren's syndrome.

Sialography shows the structural changes of the Salivary gland radiologically by infusing contrast material into the Stensen's duct, and is thought to have high sensitivity and specificity in diagnosing Sjögren's syndrome [2]. Parotid sialography correlates with the pathologic conditions, and Sjögren's syndrome shows characteristic sialectasis, dilatation of the salivary duct [10], which shows an "apple tree" or "mulberry" pattern, on the sialogram. The sialographic findings are classified into 5 stages according to the classification of Rubin and Holt [10]; normal, punctate, globular, cavitary, and destructive. The last four changes of sialectasis are thought to present increasing glandular damage caused by chronic salivary gland inflammation, and indicate a positive diagnosis according to the Sjögren's syndrome diagnostic criteria $[2,5]$.

The present results demonstrated that the simulated saliva flow was significantly related to the stages of sialography. The result is consistent with the previously reported findings that the parotid salivary flow rate stimulated by $10 \%$ citric acid was significantly lower in the sialography positive group than that in the negative group [32]. An element of myoepithelial cell hyperplasia tends to narrowing of the lumen of the interlobular ducts. Functioning acinar cells continue to secrete in a narrowed duct system resulting in retention of saliva in the intralobular ducts, which then dilate. At this stage, the sialogram shows a punctate (stage I) or globular pattern (stage II). The continued progression of periductal infiltration of predominant CD4-positive $\mathrm{T}$ lymphocytes results in salivary gland destruction is caused by perforin and granzyme A in addition to Fas-Fas ligand systemmediated apoptosis [33]. The end stage of the disease is characterized by the total absence of the glandular architecture and parenchyma atrophy, which correspond to the destructive stage on sialography; stage IV. The decrease of SSF suggested to be mainly caused by the dilation of the duct with or without parotid acinar atrophy because the sialographic findings are strongly correlated with the pathological condition [10]. A decrease of SSF should be reflected by the degree of parotid destruction since stimulated saliva is mainly secreted from the parotid gland rather than the submandibular/sublingual glands.

In conclusion, the measurement of both resting and stimulated saliva flow is significant for predicting the changes of the salivary glands because RSF reflects immunological factors and the SSF reflects the damage of the parotid gland.

\section{ACKNOWLEDGEMENTS}

This investigation was supported in part by a grant-in-aid from the Ministry of Education, Culture, Sports, Science, and Technology.

\section{REFERENCES}

[1] Fox, R.I. (2005) Sjogrens syndrome. Lancet, 366, 321331.doi:10.1016/S0140-6736(05)66990-5

[2] Kalk, W.W., Vissink, A., Spijkervet, F.K., Bootsma, H., Kallenberg, C.G. and Roodenburg, J.L. (2002). Parotid sialography for diagnosing Sjogren syndrome. Oral Surgery, Oral Medicine, Oral Pathology, Oral Radiology \& Endodontics, 94, 131-137.

[3] Fox, R.I. and Saito, I. (1994) Criteria for diagnosis of Sjogren's syndrome. Rheumatic Disease Clinics of North America, 20, 391-407.

[4] Vitali, C., Bombardieri, S., Jonsson, R., Moutsopoulos, H.M., Alexander, E.L., Carsons, S.E., Daniels, T.E., Fox, P.C., Fox, R.I., Kassan, S.S., Pillemer, S.R., Talal, N. and Weisman, M.H. (2002) Classification criteria for Sjögren's syndrome: A revised version of the European criteria proposed by the American-European Consensus Group. Annals of the Rheumatic Diseases, 61, 554-558. doi:10.1136/ard.61.6.554

[5] Fujibayashi, T., Sugai, S., Miyasaka, N., Hayashi, Y. and Tsubota K. (2004) Revised Japanese criteria for Sjögrens syndrome: Availability and validity. Modern Rheumatology, 14, 425-434. doi:10.1007/s10165-004-0338-x

[6] Konttinen, Y.T., Hukkanen, M., Kemppinen, P., Segerberg, M., Sorsa, T., Malmstrom, M., Rose, S., Itescu, S. and Polak, J.M. (1992) Peptide-containing nerves in labial salivary glands in Sjogren's syndrome. Arthritis \& Rheumatism, 35, 815-820.doi:10.1002/art.1780350717

[7] Beroukas, D., Goodfellow, R., Hiscock, J., Jonsson, R., Gordon, T.P. and Waterman, S.A. (2002) Up-regulation of M3-muscarinic receptors in labial salivary gland acini in primary Sjogren's syndrome. Laboratory Investigation, 82, 203-210.

[8] Robinson, C.P., Brayer, J., Yamachika, S., Esch, T.R., Peck, A.B., Stewart, C.A., Peen, E., Jonsson, R. and Humphreys-Beher, M.G. (1998) Transfer of human serum IgG to nonobese diabetic Igmu null mice reveals a role for autoantibodies in the loss of secretory function of exocrine tissues in Sjogren's syndrome. Proceedings of the National Academy of Sciences of the USA, 95, 75387543.doi:10.1073/pnas.95.13.7538

[9] Navazesh, M. and Christensen, C.M. (1982) A compareson of whole mouth resting and stimulated salivary measurement procedures. Journal of Dental Research, 61, 1158-1162. doi:10.1177/00220345820610100901

[10] Rubin, P. and Holt, J.F. (1957) Secretory sialography in diseases of the major salivary glands. American Journal of Roentgenology, Radium Therapy, and Nuclear Medicine, 77, 575-598.

[11] Greenspan, J.S., Daniels, T.E., Talal, N. and Sylvester, R.A. (1974) The histopathology of Sjogren's syndrome in labial salivary gland biopsies. Oral Surgery, Oral Medi- 
cine, Oral Pathology, Oral Radiology \& Endodontics, 37, 217-229.

[12] Baum, B.J. (1981) Evaluation of stimulated parotid saliva flow rate in different age groups. Journal of Dental Research, 60, 1292-1296. doi:10.1177/00220345810600070101

[13] Heft, M.W. and Baum, B.J. (1984) Unstimulated and stimulated parotid salivary flow rate in individuals of different ages. Journal of Dental Research, 63, 1182-1185. doi:10.1177/00220345840630100101

[14] Osterberg, T., Birkhed, D., Johansson, C. and Svanborg, A. (1992) Longitudinal study of stimulated whole saliva in an elderly population. Scandinavian Journal of Dental Research, 100, 340-345.

[15] Ship, J.A. and Baum, B.J. (1990) Is reduced salivary flow normal in old people? Lancet, 336, 1507. doi:10.1016/0140-6736(90)93212-8

[16] Wu, A.J., Atkinson, J.C., Fox, P.C., Baum, B.J. and Ship, J.A. (1993) Cross-sectional and longitudinal analyses of stimulated parotid salivary constituents in healthy, different-aged subjects. Journals of Gerontology, 48, M219M224.

[17] Scott, J., Flower, E.A. and Burns, J. (1987) A quantitative study of histological changes in the human parotid gland occurring with adult age. Journal of Oral Pathology, 16, 505-510. doi:10.1111/j.1600-0714.1987.tb00681.x

[18] Scott, J. (1977) Degenerative changes in the histology of the human submandibular salivary gland occurring with age. Journal de Biologie Buccale, 5, 311-319.

[19] Nagler, R.M. and Hershkovich, O. (2005) Relationships between age, drugs, oral sensorial complaints and Salivary profile. Archives of Oral Biolog, 50, 7-16. doi:10.1016/j.archoralbio.2004.07.012

[20] Pedersen, W., Schubert, M., Izutsu, K., Mersai, T. and Truelove, E. (1985) Age-dependent decreases in human submandibular gland flow rates as measured under resting and post-stimulation conditions. Journal of Dental Research, 64, 822-825. doi: $10.1177 / 00220345850640050801$

[21] Gresik, E.W. and Azmitia, E.C. (1980) Age related changes in NGF, EGF and protease in the granular convoluted tubules of the mouse submandibular gland. A morphological and immunocytochemical study. Journals of Gerontology, 35, 520-524.

[22] Gresik, E.W. (1989) Changes with senescence in the fine structure of the granular convoluted tubule of the submandibular gland of the mouse. American Journal of Anatomy, 184, 147-156. doi:10.1002/aja.1001840206

[23] Ishikawa, Y., Gee, M.V., Ambudkar, I.S., Bodner, L., Baum, B.J. and Roth, G.S. (1988) Age-related impairment in rat parotid cell alpha 1-adrenergic action at the level of inositol trisphosphate responsiveness. Biochimica et Biophysica Acta, 968, 203-210. doi:10.1016/0167-4889(88)90009-2

[24] Hiratsuka, K., Kamino, Y., Nagata, T., Takahashi, Y., Asai,
S., Ishikawa, K. and Abiko, Y. (2002) Microarray analysis of gene expression changes in aging in mouse submandibular gland. Journal of Dental Research, 81, 679-682. doi:10.1177/154405910208101005

[25] Houghton, K., Malleson, P., Cabral, D., Petty, R. and Tucker, L. (2005) Primary Sjogren's syndrome in children and adolescents: Are proposed diagnostic criteria applicable? Journal of Rheumatology, 32, 2225-2232.

[26] Dawes, C. (1996) Factors influencing salivary flow rate and composition. In: Edgar, W.E. and O'Mullane, D.M., Eds., Saliva and Oral Health, 2nd Edition, Brithsh Dental Association, London, 27-41.

[27] Cha, S., Peck, A.B. and Humphreys-Beher, M.G. (2002) Progress in understanding autoimmune exocrinopathy using the non-obese diabetic mouse: An update. Critical Reviews in Oral Biology \& Medicine, 13, 5-16. doi: $10.1177 / 154411130201300103$

[28] Haneji, N., Nakamura, T., Takio, K., Yanagi, K., Higashiyama, H., Saito, I., Noji, S., Sugino, H. and Hayashi, Y. (1997) Identification of alpha-fodrin as a candidate autoantigen in primary Sjogren's syndrome. Science, 276, 604-607. doi:10.1126/science.276.5312.604

[29] Robinson, C.P., Yamachika, S., Alford, C.E., Cooper, C., Pichardo, E.L., Shah, N., Peck, A.B. and Humphreys-Beher, M.G. (1997) Elevated levels of cysteine protease activity in saliva and salivary glands of the nonobese diabetic (NOD) mouse model for Sjogren syndrome. Proceedings of the National Academy of Sciences of the USA, 94, 5767-5771. doi:10.1073/pnas.94.11.5767

[30] Robinson, C.P., Bounous, D.I., Alford, C.E., Nguyen, K.H., Nanni, J.M., Peck, A.B. and Humphreys-Beher, M.G. (1997) PSP expression in murine lacrimal glands and function as a bacteria binding protein in exocrine secretions. American Journal of Physiology, 272, G863G871.

[31] Humphreys-Beher, M.G., Brinkley, L., Purushotham, K.R., Wang, P.L., Nakagawa, Y., Dusek, D., Kerr, M., Chegini, N. and Chan, E.K. (1993) Characterization of antinuclear autoantibodies present in the serum from nonobese diabetic (NOD) mice. Clinical Immunology \& Immunopathology, 68, 350-356. doi:10.1006/clin.1993.1137

[32] Saito, T., Fukuda, H., Arisue, M., Matsuda, A., Shindoh, M., Amemiya, A. and Ohmori, K. (1991) Relationship between sialographic findings of parotid glands and histopathologic finding of labial glands in Sjogren's syndrome. Relation to clinical and immunologic findings. Oral Surgery, Oral Medicine, Oral Pathology, 72, 675680.doi:10.1016/0030-4220(91)90009-2

[33] Matsumura, R., Umemiya, K., Kagami, M., Tomioka, H., Tanabe, E., Sugiyama, T., Sueishi, M., Nakajima, A., Azuma, M., Okumura, K. and Sumida, T. (1998) Glandular and extraglandular expression of the Fas-Fas ligand and apoptosis in patients with Sjogren's syndrome. Clinical \& Experimental Rheumatology, 16, 561-568. 